Journal Of Al Azhar University Engineering Sector

VOL. 11, NO. 39, APRIL 2016, 579-590

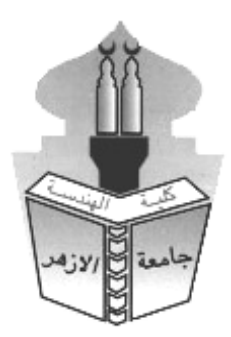

\title{
LEED RATING SYSTEM APPLICATION ON EL-DAKAHLIA GOVERNMENTAL HEADQUARTER BUILDING TOWARDS BETTER SUSTAINABLE PERFORMANCE AND ECOFRIENDLY BUILDING
}

\author{
Hossam Elsharkawi ${ }^{1}$, Alaa El-Eishy ${ }^{2}$ and Ahmed El-Tantawy ${ }^{2}$ \\ ${ }^{1}$ Researcher, Department of Architecture, Faculty of Engineering, Mansoura University \\ ${ }^{2}$ Department of Architecture, Faculty of Engineering, Mansoura University
}

\begin{abstract}
The overriding purpose of this paper is to determine the relative importance of the application of LEED (Leadership in Energy and Environmental Design) rating system as a curriculum organizer Tools for getting a sustainable and eco-friendly building and community as well in Egypt. Throughout the application and assessment process on the proposed case study ElDakahlia Governmental Headquarter building (Existing Building - Major Renovation) as a case study to achieve sustainability requirements which results in renovate and promote the existing building according to LEED Rating System Requirements towards a sustainable and ecofriendly buildings and urban communities consequently[1].
\end{abstract}

\section{Keyword : LEED, Green Building, Sustainability, Urban Community.}

\section{INTRODUCTION}

Due to that El-Dakahlia Governmental building Headquarter is a service-based building for more than 6 million people, it's a unique location in the center of Al Mansoura City, which located at front of Nile River and surrounded with related many important governmental service building, therefore El-Dakahlia Governmental building Headquarter has been selected to be our value case study for Appling a suitable and relevant LEED rating systems to promote and improve its efficiency with full respect to Triple Bottom Line (Environment, Economic and Human) (Fig.1) and specifically in energy Efficiency inside the building which lead to reduces the environmental harms of buildings and restores the balance of natural systems[2]. Appling LEED rating system on the nominated building will result in Environment, Economic, and Human impacts inside and outside the building and will reflect the productivity of employee and the absenteeism percent of employee as well.

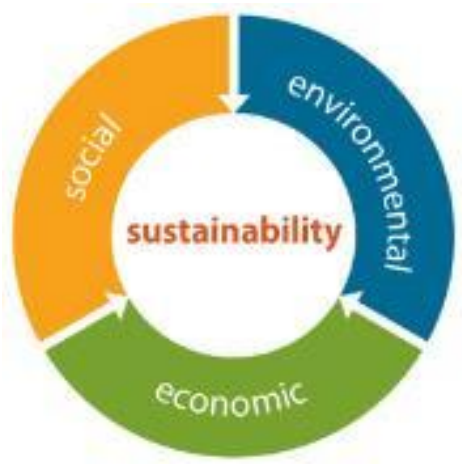

Fig.1: Triple Bottom Line 
The nominated building has been designed and constructed earlier according to the constant architecture design, which conforms to the existing Environment in lack of simulation design tools at that time. Although the Internal Patio and open to sky areas have been considered and incorporated in design along with a unique architecture configuration, but the building did not achieve the desired sustainable performance, such as using artificial lighting throughout daytime due to insufficient natural daylight provision and in addition to improper external architecture treatment for sunshade...etc.

Thus this paper aims to:

* Environmental Benefits of green building [3] enhance and protect ecosystem and biodiversity, improve air and water quality, reduce solid waste and conserve natural resources (Fig.2).

* Provide higher levels of indoor quality and comfort over conventional design and construction practices and provide higher levels of occupant satisfaction with regards to air quality and lighting, where studies indicate significant gains with occupant productivity and show that these benefits can translate into a $2 \%$ to $16 \%$ increase in employee productivity [4].

* Economic benefits of Green building include reduce the operating cost, enhance asset $\backslash$ profits, improve employee satisfaction and productivity and optimize life cycle economic performance throughout the entire life cycle of a project (Fig.2).

* Less energy usage, lower maintenance costs and Lower CO2 emissions [5]

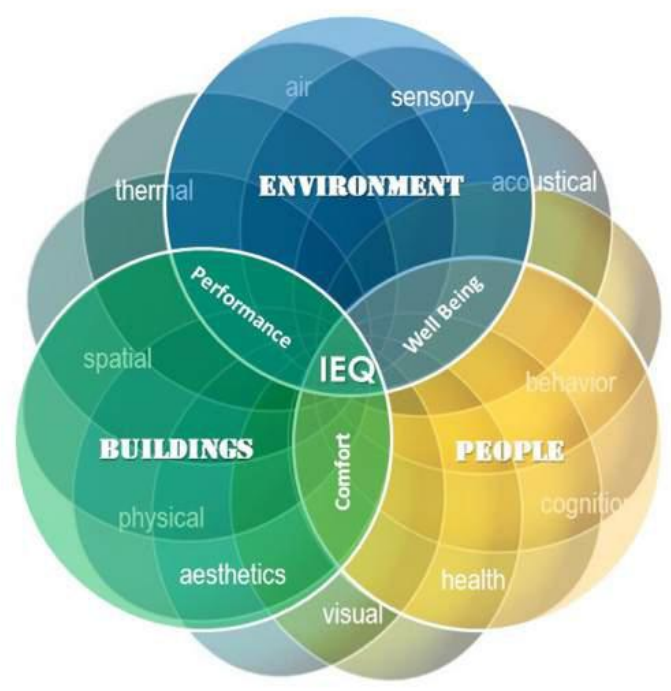

Fig.2: Sustainable Place Experience Layers

\section{METHODOLOGY}

The methodology of the main concept herein is modeling the nominated building by Autodesk Vasari Program, the mass to be modeled as a mass only without existing opening and apply all modeling recommendations according LEED requirements on the original building mass, then the revised building mass to be run again to verify all application results. To achieve and imply relevant LEED rating systems on the selected building, there are many prospective impacts and changes will be happened and placed on the external elevation, internal and finally major renovation will be considered as well to get and achieve the desired targets.

\section{LEED APPLICATION STRATEGIES \\ 3.1 Existing Condition Analysis}

El-Dakahlia Governmental Headquarter Building located on the center of Mansoura city and front of the Nile River side which giving the building a prestigious and value location, the prevailing wind directed from North-West direction and Sun path around building through all seasons going around building as illustrated thro Fig No. for Math curved shape has been nominate by designer which indicate the flexibility even inside Functionality or outside aesthetically, also Internal patio areas are provided and incorporated inside the building. 
Although all of the above consideration have been implemented and executed, but the desired Natural daylight, Fresh/ Natural air and connectivity with the Environment not achieved as required inside building, which are demonstrated though using artificial lighting during daytime working hours refer to Fig No., also vertical sunshade fins treatment are interrupting the natural daylight penetration inside the building and also the connectivity with the external environment...etc. Due to these inaccurate architectural treatments which are the main cause of lower employee productivity, costly electricity bill and being non healthy environment inside the building and therefore and to improve the building sustainable performance and getting an ecofriendly building, relevant LEED rating system to be implemented on the nominated building accordingly.

\subsection{Running Energy modeling process on the existing building for evaluation the existing condition}

El-Dakahlia Governmental Headquarter Building will be analyzed in detail from Siting (Fig.3), Massing and orientation, Building Envelope Performance, Thermal Comfort Ranges, Indoors and Outdoors Water Demand and Consumption, Architecture treatments, ...etc. and its impacts on the Energy efficiency use and water consumption and indoor air quality and its impacts on the employee productivity and occupant satisfaction as well. Finally all outcomes and results (Fig.6, 7, 8, 9) will be analyzed and verified through computation modeling program called Autodesk Vasari.

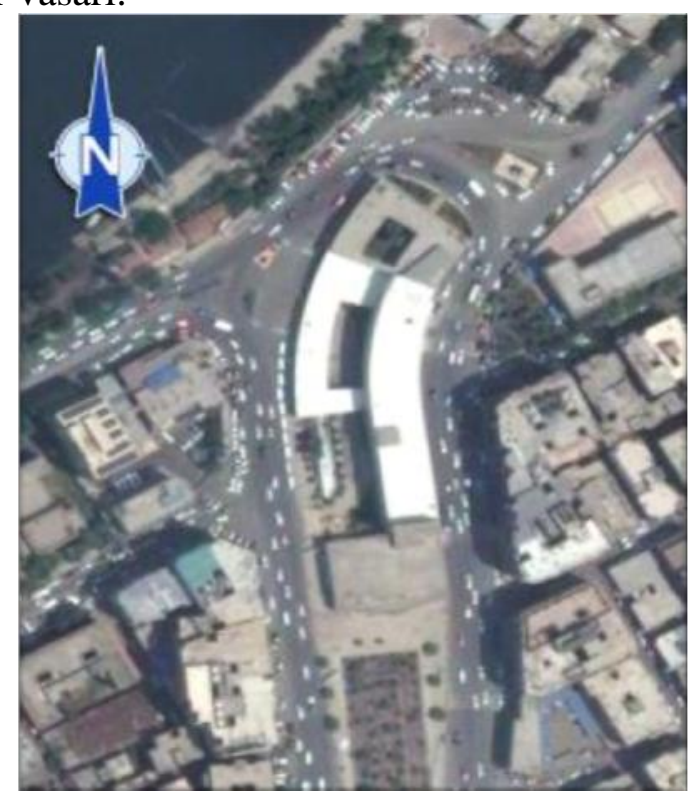

Fig.3: Site Location of Case Study- source Google Earth Map

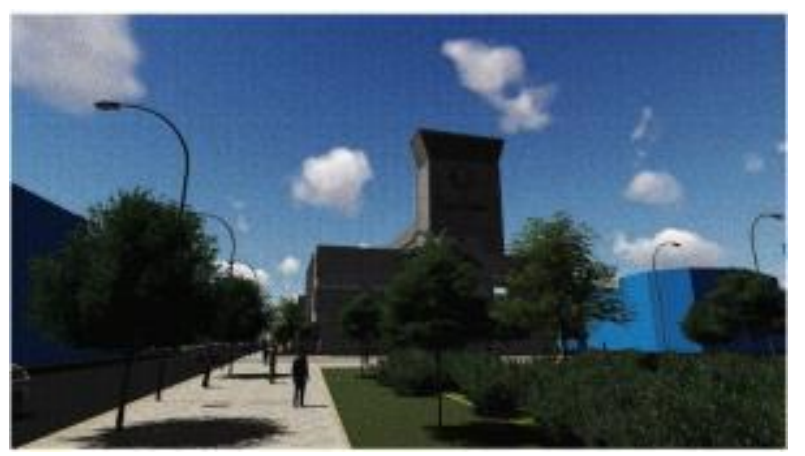

Fig.4: Exterior shot indicating surrounding environment

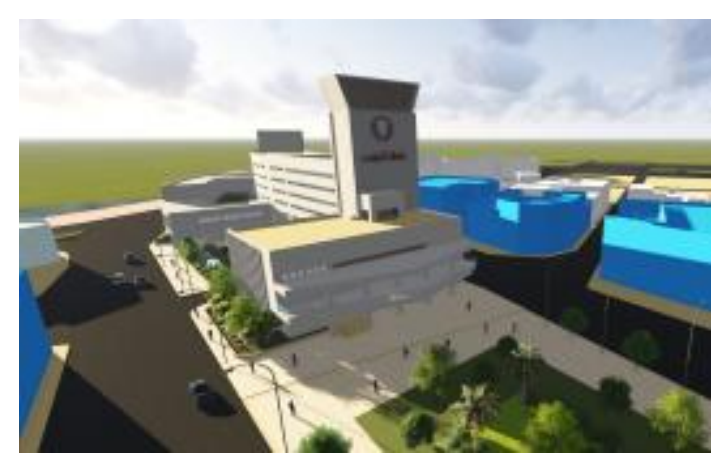

Fig.5: Exterior perspective El-

Dakahlia governmental headquarter building 


\subsection{Solar radiation Study}

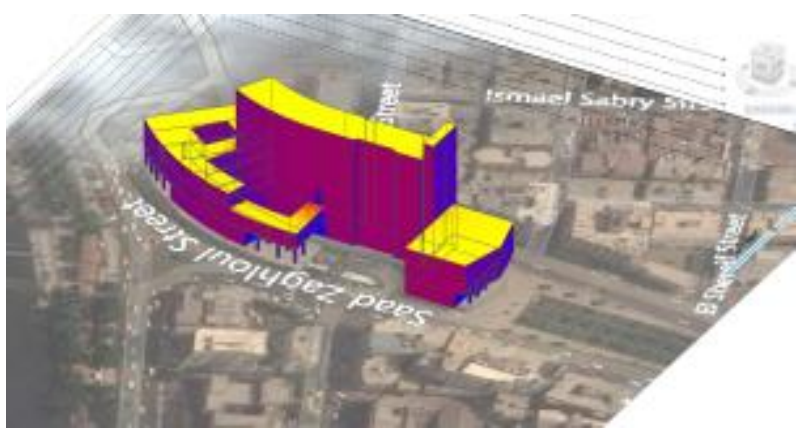

Fig.6: Solar Radiation in summer

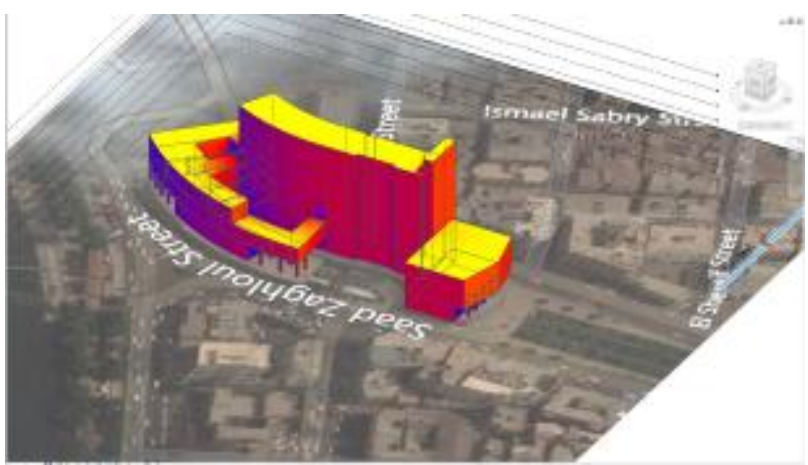

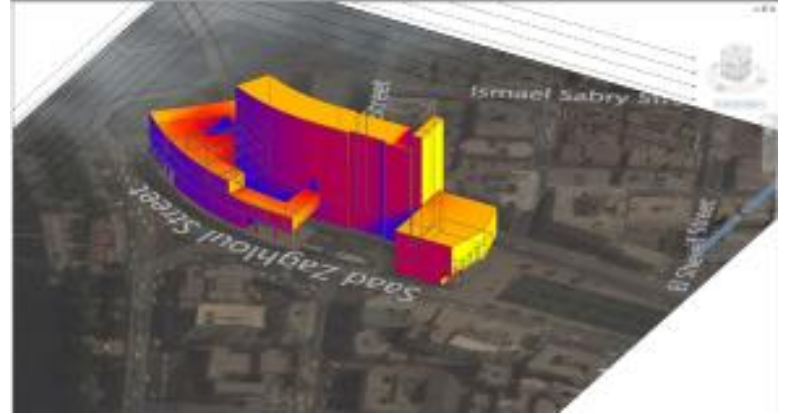

Fig.7: Solar Radiation in winter

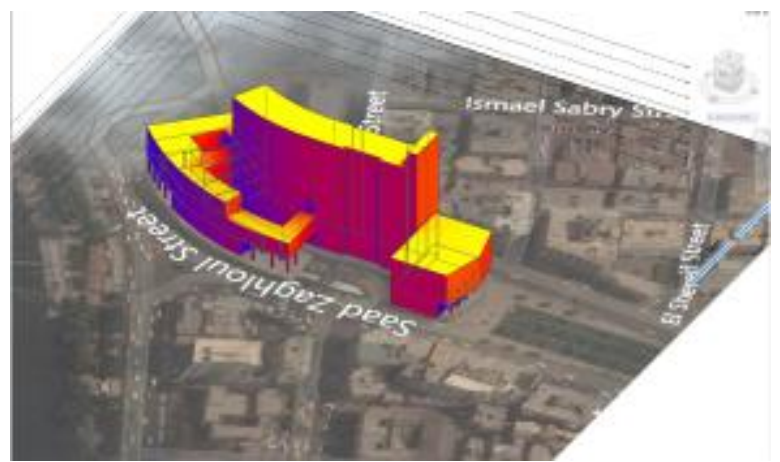

Fig.9: Solar Radiation in fall

Fig.8: Solar Radiation in spring

As a result from Solar Radiation Modeling analysis, in summer season indicates that the maximum direct solar radiation placed on the horizontal surface (Fig.6), which is comparable and the same to spring and fall seasons as well (Fig.8, 9, 12), therefore solution of thermal treatment (Fig.6, 7, 8, 9) is requested and to be applied on roof surface to prevent solar heat penetration/ transference inside the building. For vertical elevations as illustrated in (Fig.6, 7, $8,9,12$ ) and due to official daily working hours up to 2:00 PM, vertical architecture fines are the best solution for current case study.

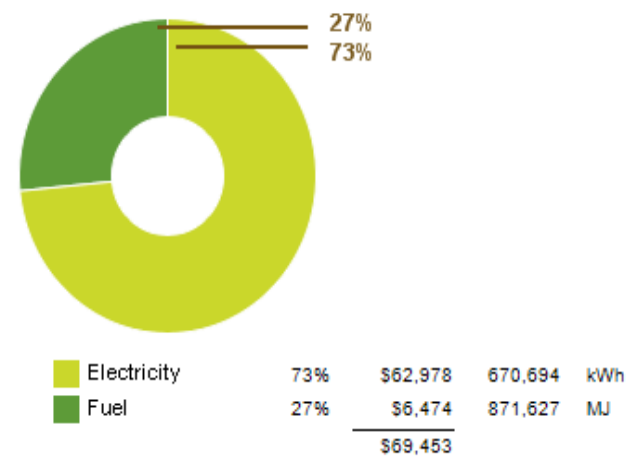

Fig.10: Estimated Annual Energy Usage/Cost

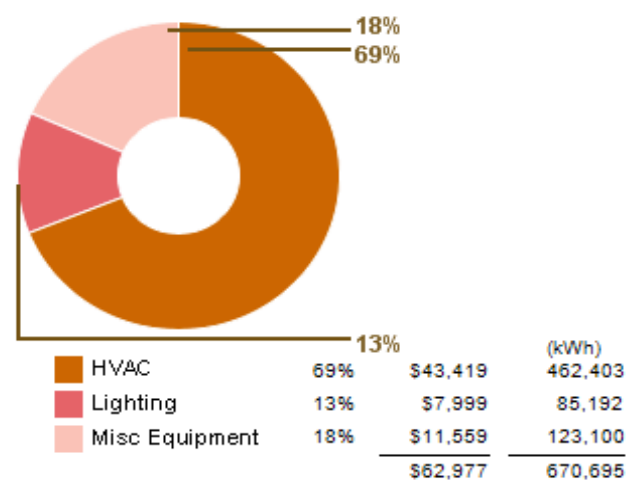

Fig.11: Estimated Energy Use: Electricity

Estimated Energy Usage (Fig.IU, II) illustrates the total Energy amount in KWh per year, which will be the benchmarkl baseline reference for improvement performance and comparison between after and before. 
LEED RATING SYSTEM APPLICATION ON EL-DAKAHLIA GOVERNMENTAL HEADQUARTER BUILDING TOWARDS BETTER SUSTAINABLE PERFORMANCE AND ECOFRIENDLY BUILDING

\subsection{Sun path around building through all seasons}

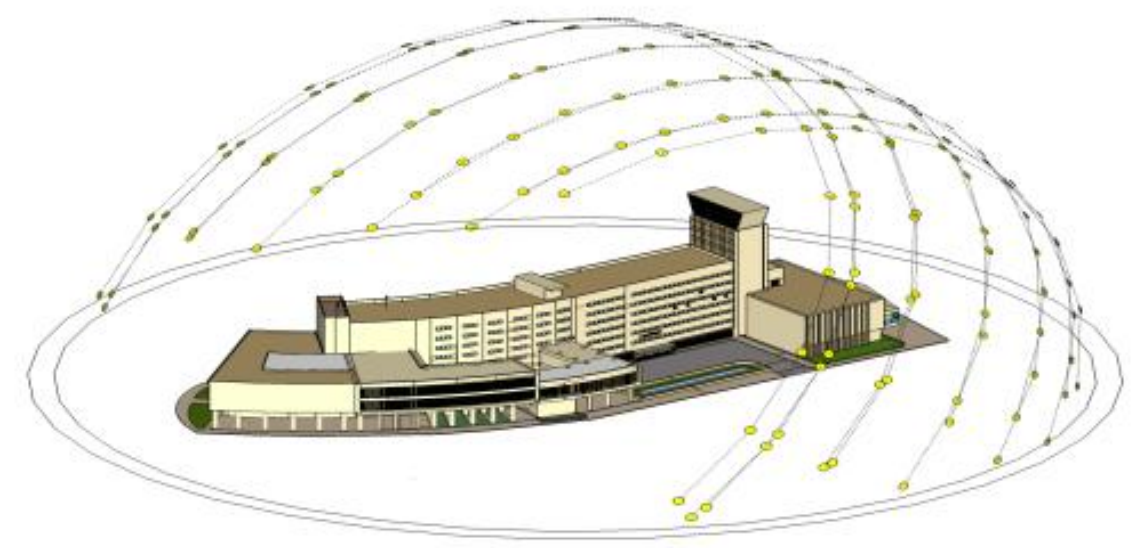

Fig.12: Sun path around building through all seasons

\subsection{Annual Wind Rose}
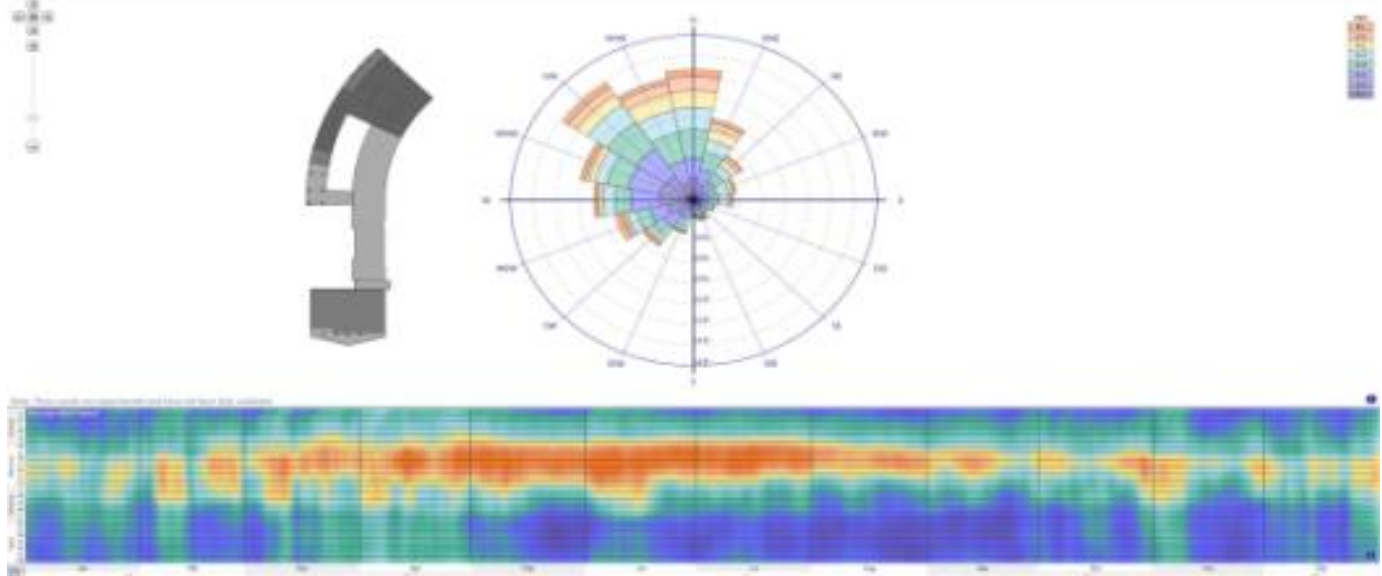

Fig.13: Annual Wind Directions

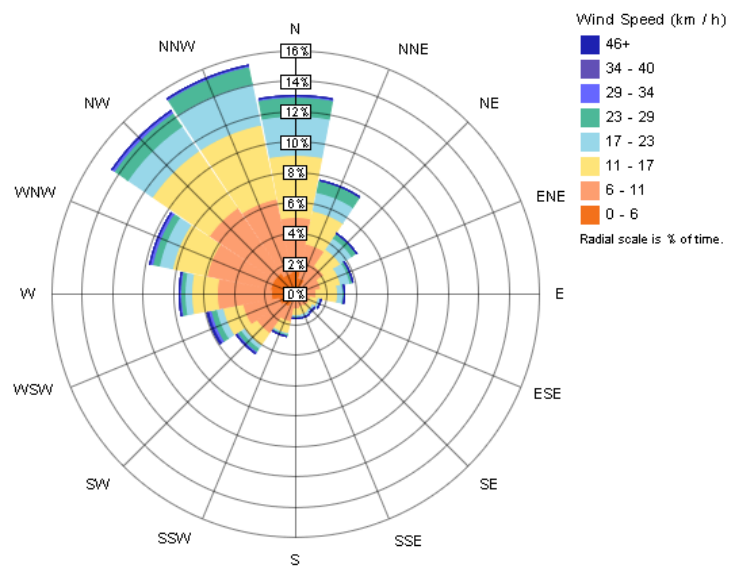

Fig.14: Annual Wind Rose (Frequency Speed)

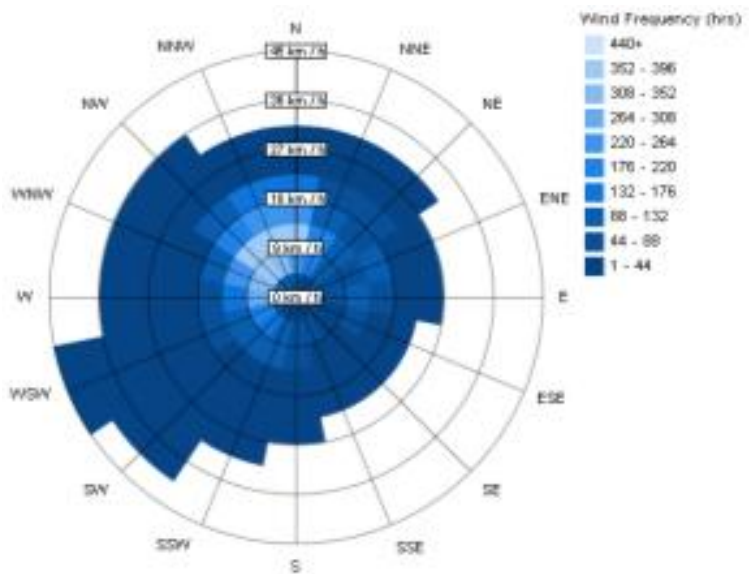

Fig.15: Annual Wind Rose (Frequency Distribution) 
LEED RATING SYSTEM APPLICATION ON EL-DAKAHLIA GOVERNMENTAL HEADQUARTER BUILDING TOWARDS BETTER SUSTAINABLE PERFORMANCE AND ECOFRIENDLY BUILDING

\subsection{Monthly Wind Roses}
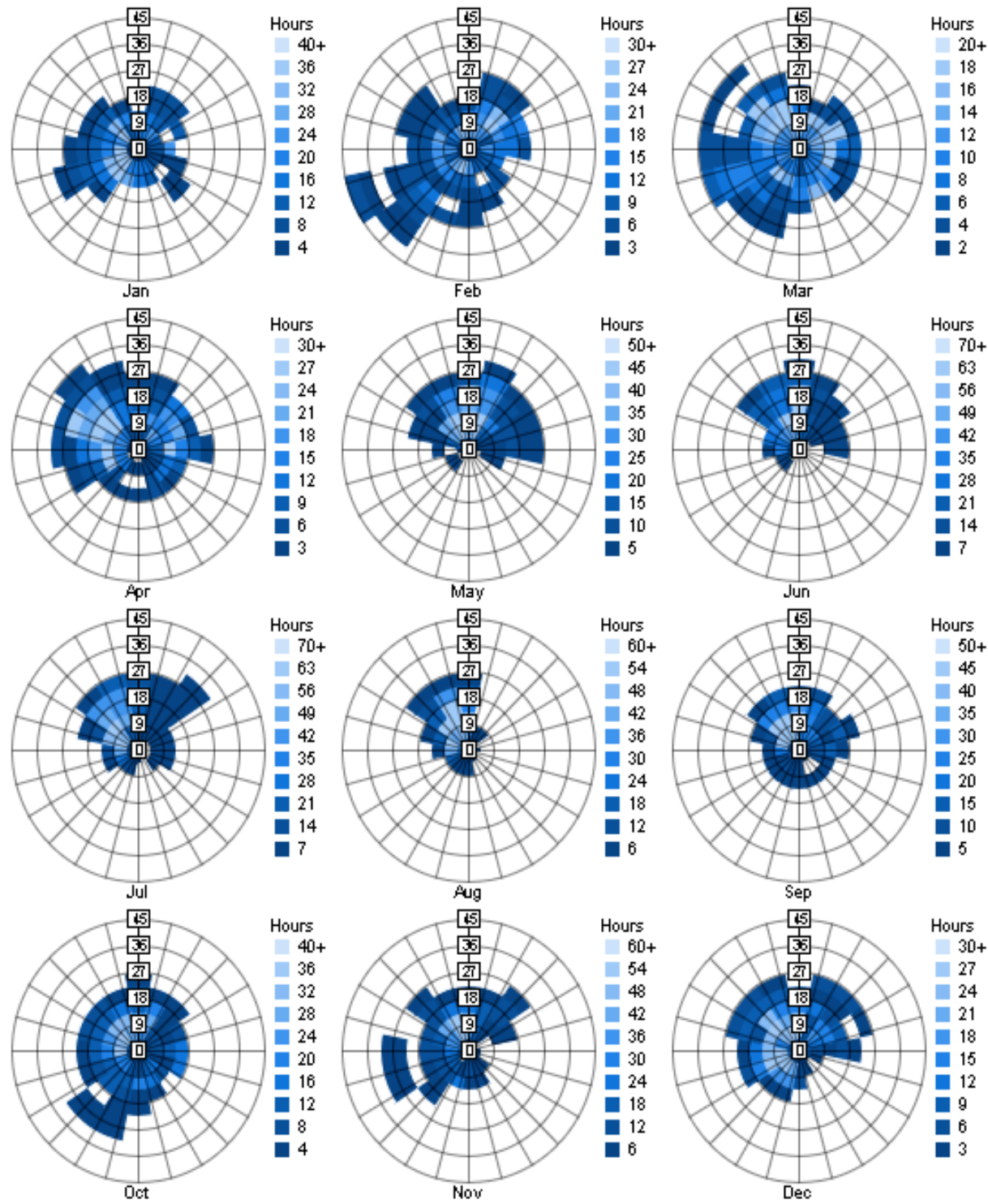

Fig.16: Monthly Wind Rose (Frequency Distribution)

\subsection{Annual/ Seasonal Shading Time}

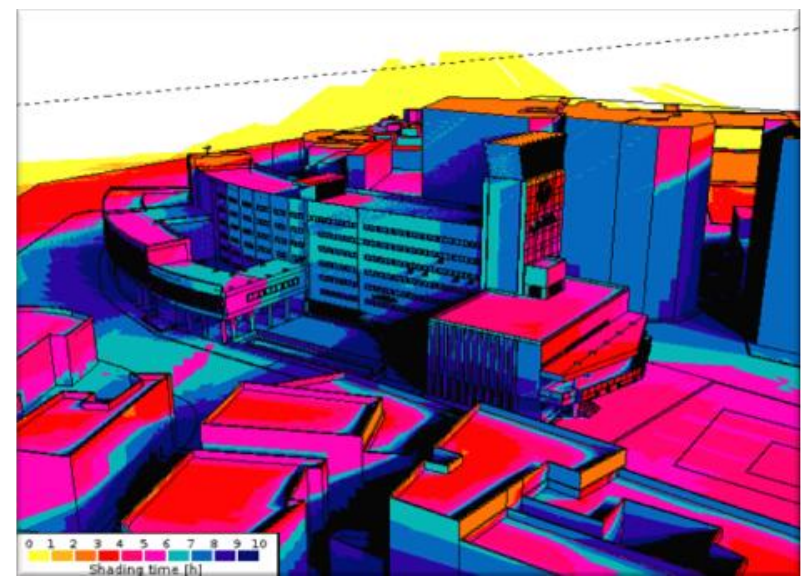

Fig.17 Shading Time on 1st January 2015 at West Elevation

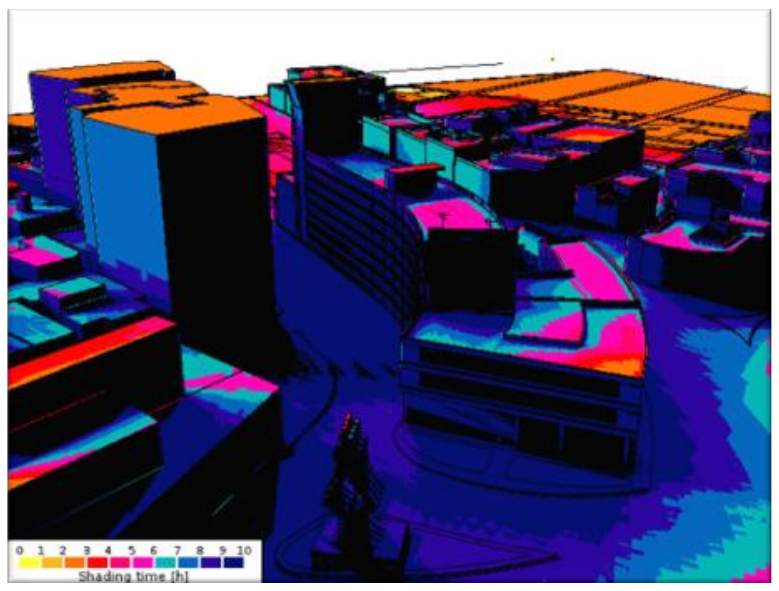

Fig.18 Shading Time on 1st January 2015 at East Elevation 


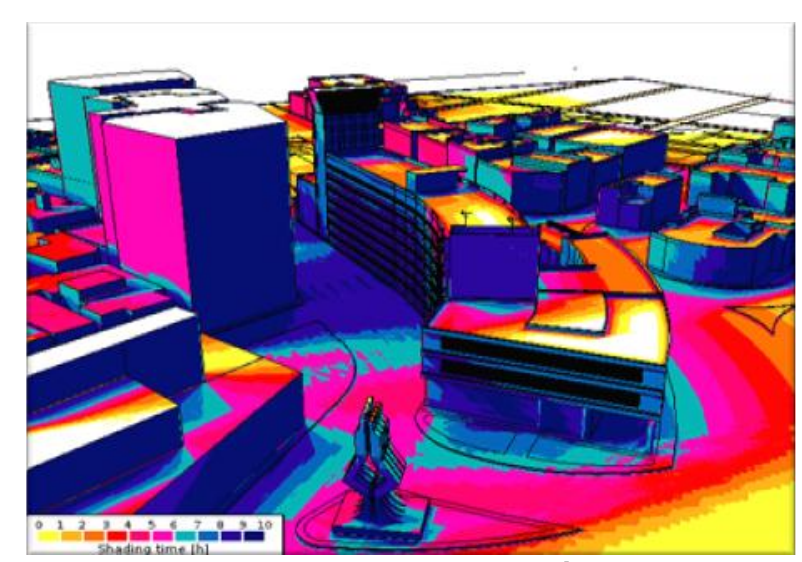

Fig.19 Sun path from $12^{\text {th }}$

March 2015 at East Elevation

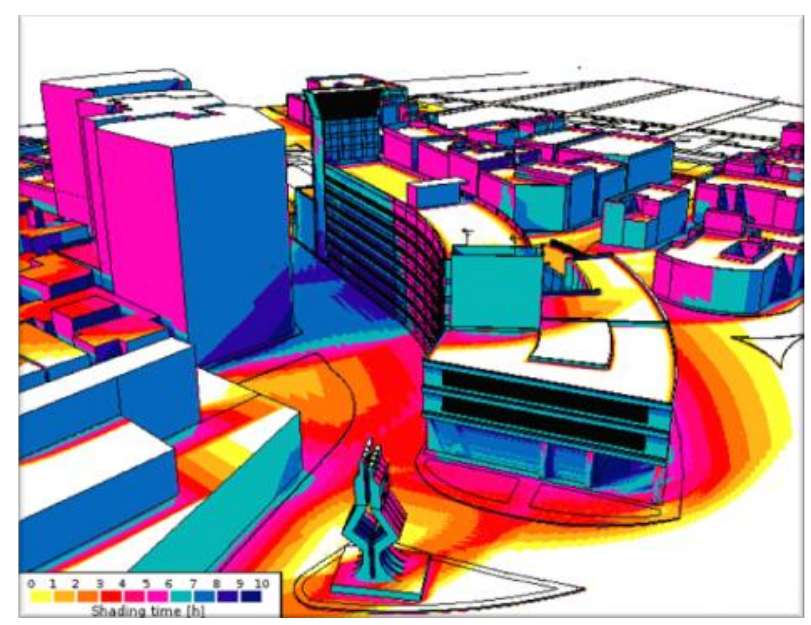

Fig.21 Sun path from 15th June 2015 at East Elevation

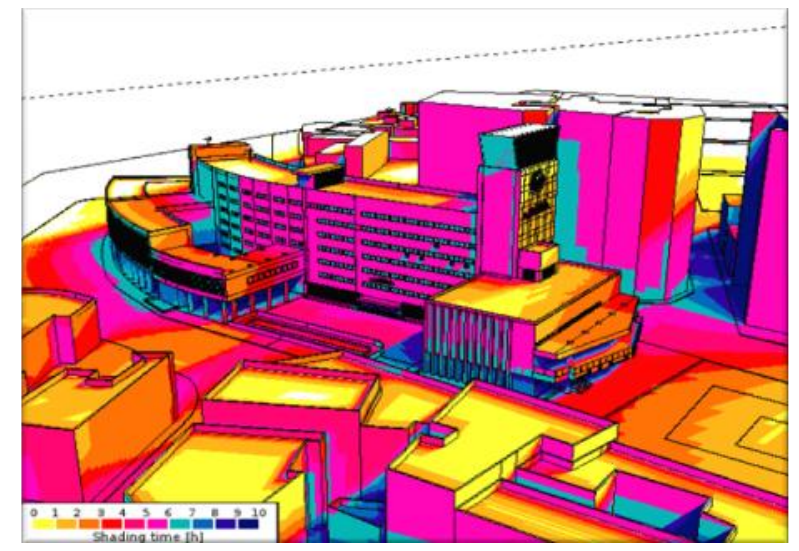

Fig.20 Sun path from 12th

March 2015 at West Elevation

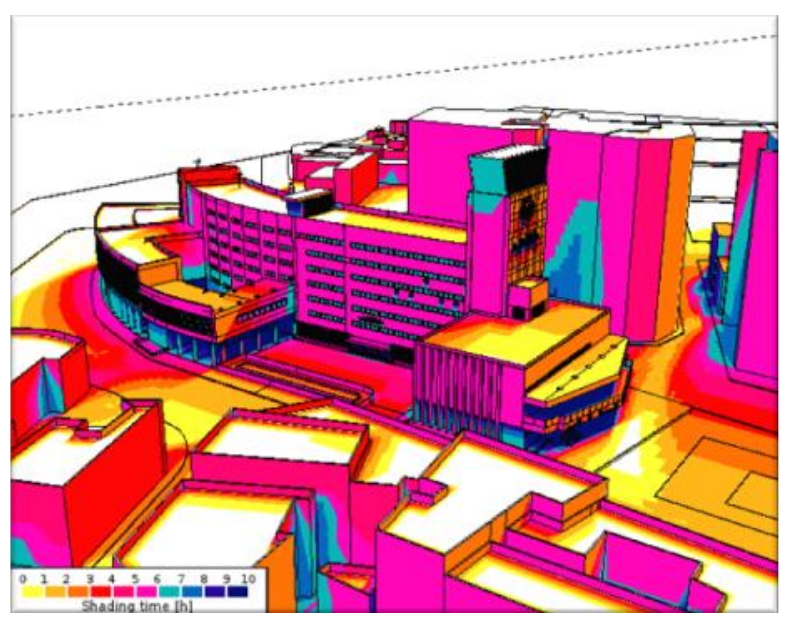

Fig.22 Sun path from 15th June 2015 at West Elevation

Shading time yearly as illustrates in the above modeling outputs (Fig.17, 18, 19, 20, 21, 22), generally Indicate being a specific areas to be provided with shade treatment specially in West and South Elevation, which have to be considered in the revised Design proposal for better performance.

\section{ANALYSIS AND FINDING INSIGNIFICANT DESIGN SOLUTION.}

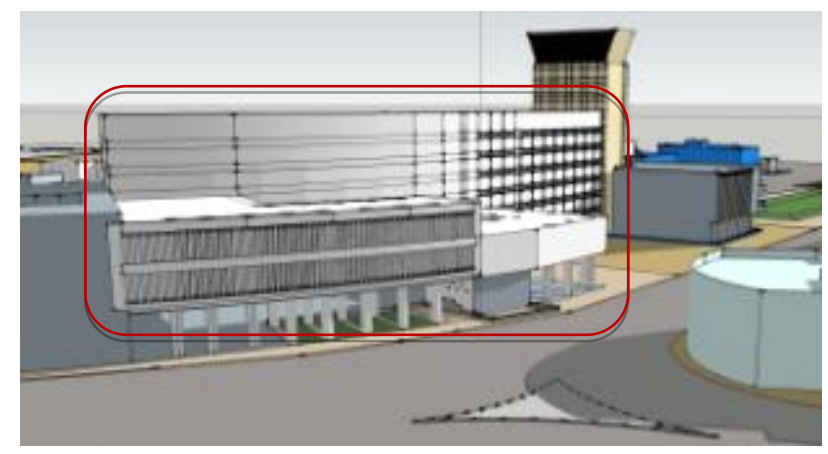

Fig.23 Improper Design for Fixed vertical sunshades and window shape

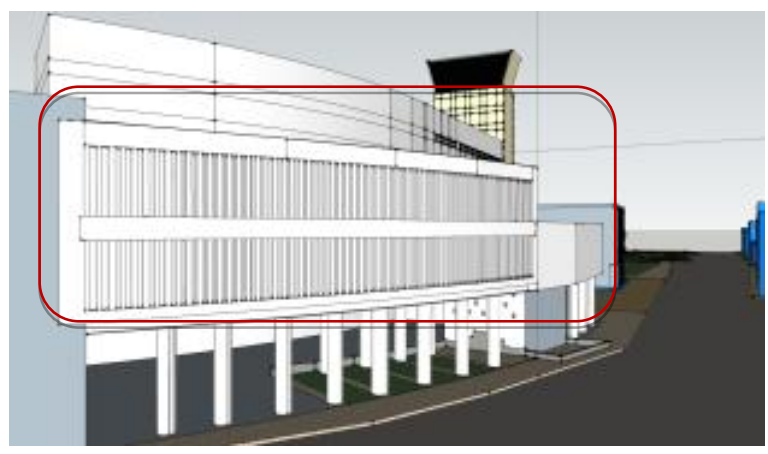

Fig.24 Improper Design for window shape and glazing material selection 


\subsection{Energy and Atmosphere (EA)}

The Energy and Atmosphere (EA) category addressing energy use reduction, energy-efficient design strategies and renewable energy sources [6]. The Energy efficiency in a green building focus on designs that reduces overall energy needs, such as double skin glazing selection, and the choice of climate-appropriate building materials. Strategies such as passive heating and cooling, natural ventilation, daylight, and high-efficiency HVAC systems with smart controls reduce a building's energy use, also the generation of renewable energy on the case study allows portions of the remaining energy consumption to be met with non-fossil fuel energy and decrease the demand for traditional sources.

\subsection{Natural Daylight}

Natural daylight will promote occupants' productivity and will decrease energy consumption as well. To get indoor natural daylight and good ventilation inside the building, windows sizes have to be redesigned and enlarged to get enough and required amount of natural light inside the building and provide a wider operable glazed windows around internal patios for getting a desired natural daylight and well ventilated areas as well, all of these will reduce the independency on the artificial lighting and electrical air condition which will result in energy saving. In addition to the above proper and relevant thermal double skin Glazing material selection to be considered to reduce and minimize heat transferring in and out to prevent escalation of energy consumption.

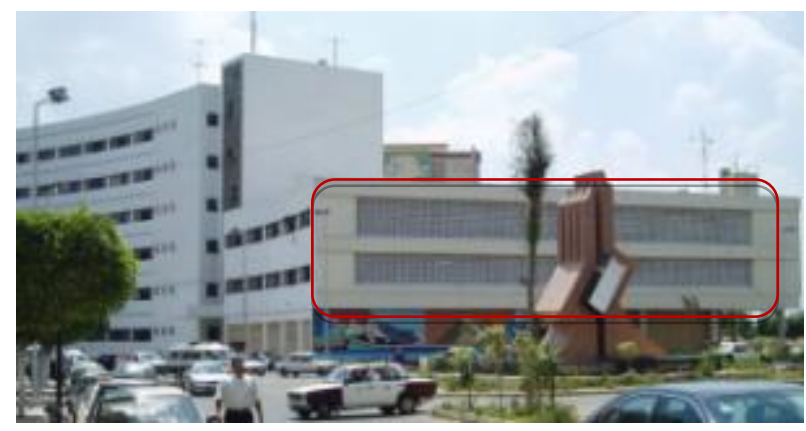

Fig25 Incorrect architecture shade treatment in north Elevation

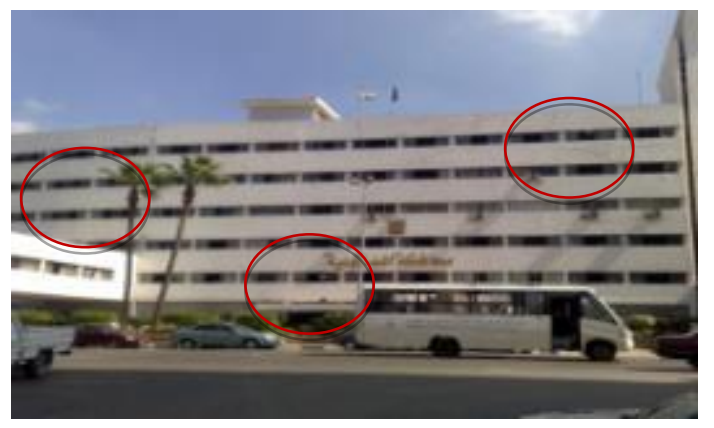

Fig.26 Artificial lightings are switched on through daytime

To avoid such that incorrect and inaccurate solutions (Fig.23, 24, 25, 26), which lead to increase the energy consumption, the building mass and volume have been analyzed in Vasari program to get the right solution by finding and catching the critical design issue which escalating Energy Consumptions. As per LEED requirements that the interior spaces have to be provided with sufficient daylight by introducing daylight into all regularly occupied spaces considering glare control to reduce the use of electrical lighting. Therefore the external elevation of Governmental building Headquarter has to be provided with windows opening larger than existing sizes (Fig.23) and considering glazing with thermal breaker, sound proof, and reflective and tented glass to achieve the desired requirement

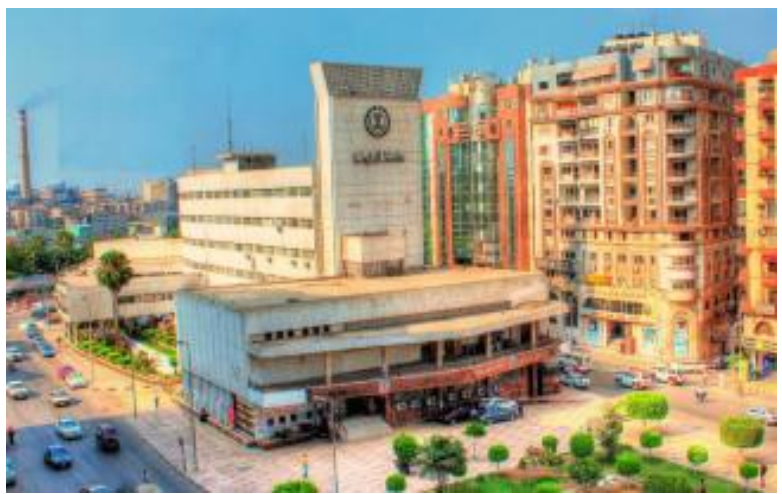

Fig.27: Existing condition for case study Building 


\section{Upgrading and promoting Existing Envelope building after analysis process 5.1 Energy and Open spaces}

Creating exterior accessible open space (Fig.28) encourages interaction with the environment, social interaction, passive recreation, and physical activities providing the governmental headquarter building with accessible vegetated open spaces which will promote positive environmental benefits - habitat creation, linked habitat corridors in urban areas, increased rainwater infiltration, Thermal Insulation and reduced heat island effect.

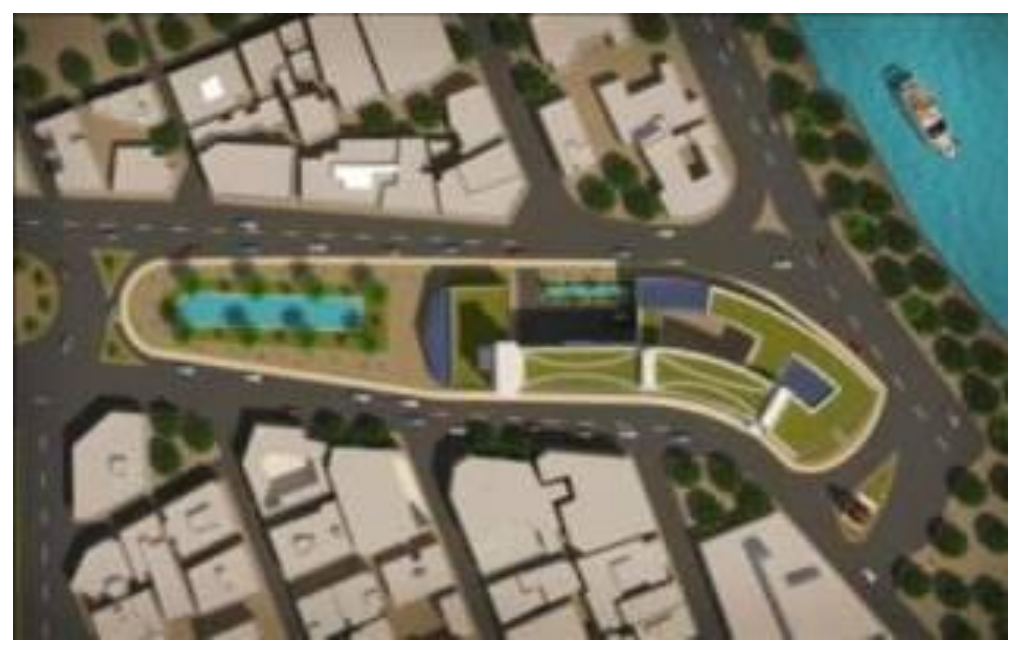

Fig.28 Site layout indicating green roof as a thermal insulation leads to Energy saving

\subsection{Natural Daylight}

According to LEED requirements, the interior spaces (Fig.32, 34) have to be provided with sufficient daylight by introducing daylight into all regularly occupied spaces considering glare control to reduce the use of electrical lighting. Therefore the external elevation of Governmental building Headquarter has to be provided with windows opening larger than existing sizes and considering glazing with thermal breaker, sound proof, and reflective and tented olace to achieve the decired remirements.

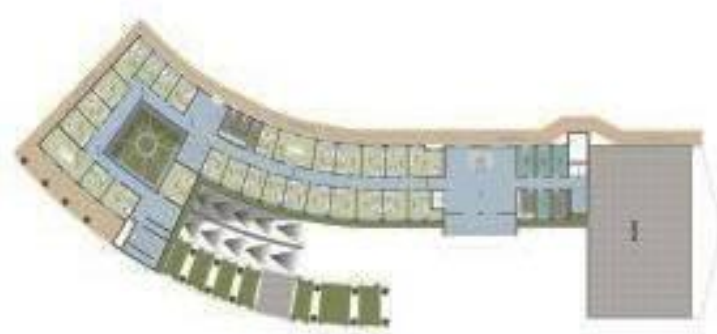

Fig.29 : Revised Ground floor plan as per LEED requirement

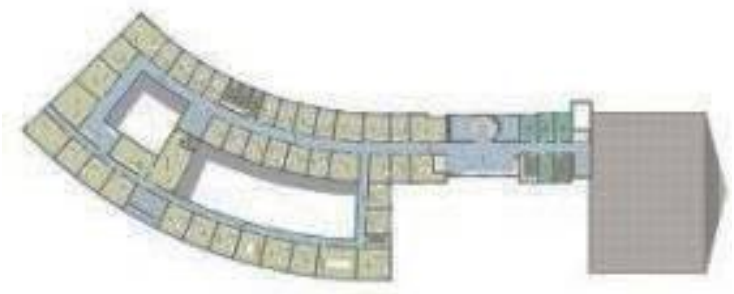

Fig.30 : Revised First Floor plan as per LEED requirement

Along with the external elevations major renovation to achieve LEED Rating system, also all Floor plans got changes to improve the connectivity between outside and inside the building such as providing glass partition instead of block walls (Fig.33, 34). As a result of revised internal plans and it's major impact on sustainability, Gypsum wall with glass partition placement instead of existing wall will achieve recycling material as a part of material and resources requirements and considered as a better future Extension solution and using interior paints, coatings, adhesives, sealants, flooring, composite wood, ceilings, walls, and thermal and acoustic insulation that achieving low emitting materials will promotes sustainability as well. 
LEED RATING SYSTEM APPLICATION ON EL-DAKAHLIA GOVERNMENTAL HEADQUARTER BUILDING TOWARDS BETTER SUSTAINABLE PERFORMANCE AND ECOFRIENDLY BUILDING

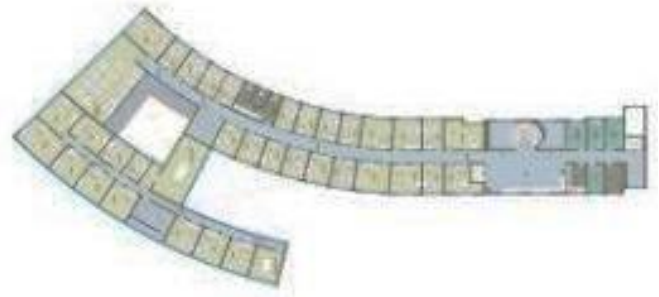

Fig.31: Revised Second floor plan as ner I.FED renuirement

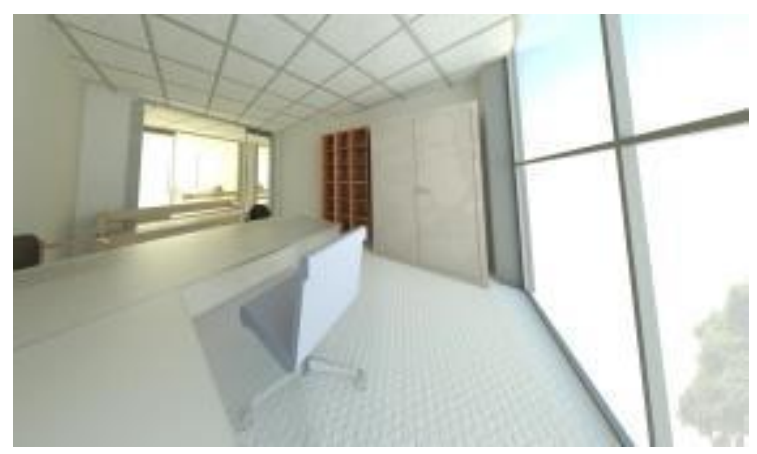

Fig.33: Interior shot for typical office - Daylight

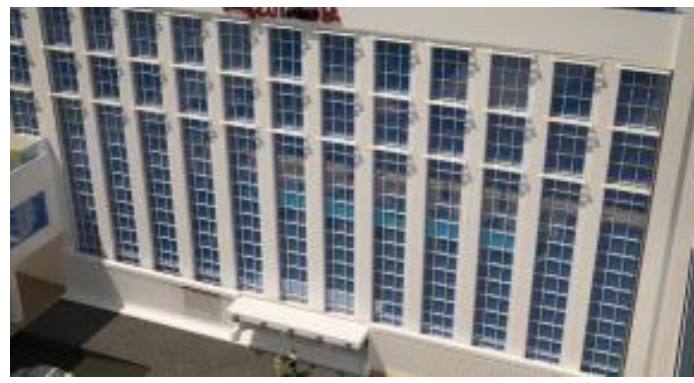

Fig.35: Revised West Elevation Curtain Wall Unit with double skin glass

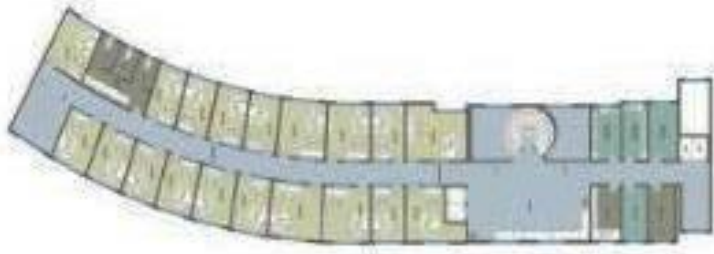

Fig.32 : Revised Typical Floor plan as per LEED requirement

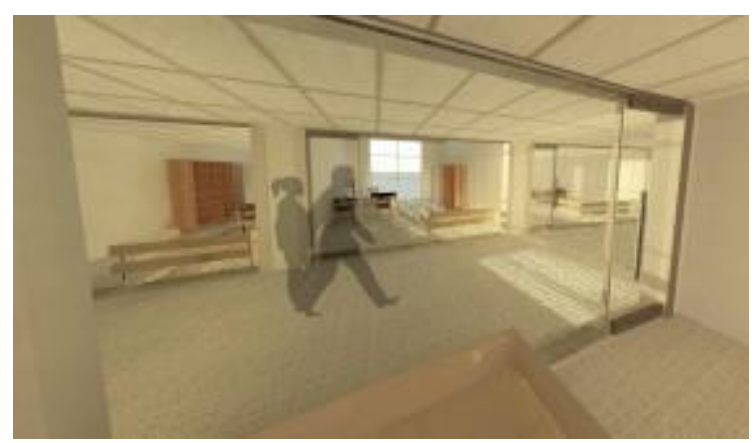

Fig.34 : Interior shot in main corridor indicates daylight Usage instead of artificial lighting

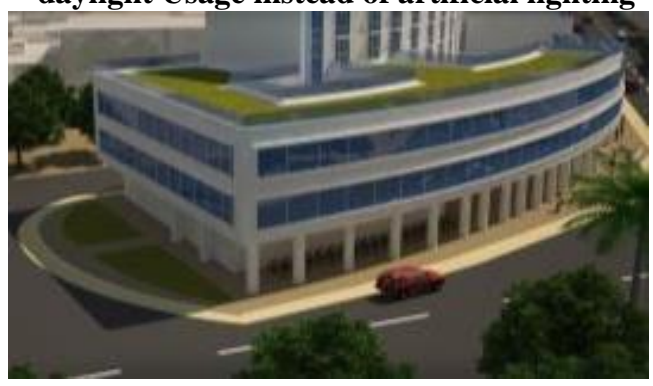

Fig.36: Revised North and West Elevations

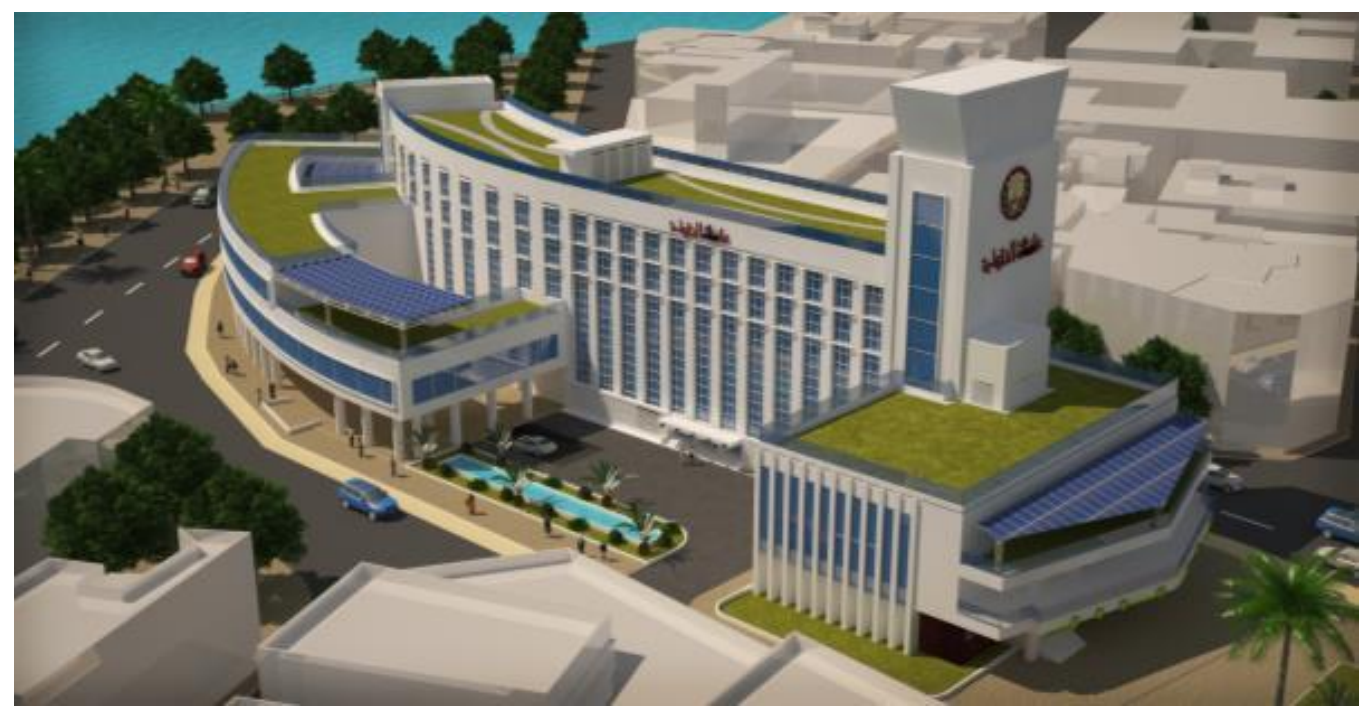

Fig.37: Revised Envelope configuration of Existing Building as a result of LEED compliance for Better Performance 


\subsection{Results of Running Energy modeling process on the revised building}

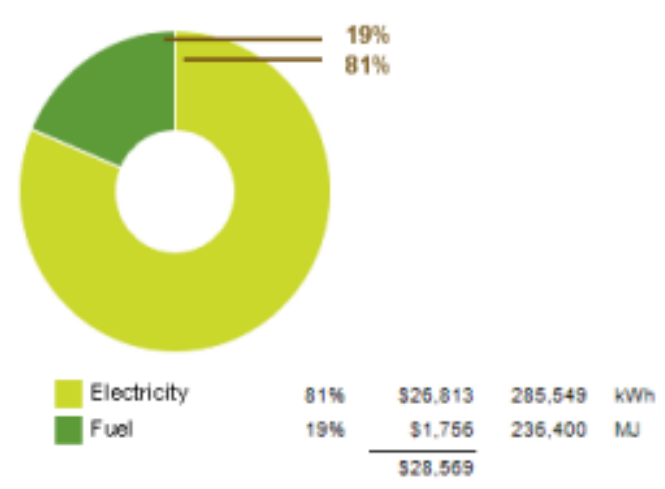

Fig.38: Annual Energy Use/Cost

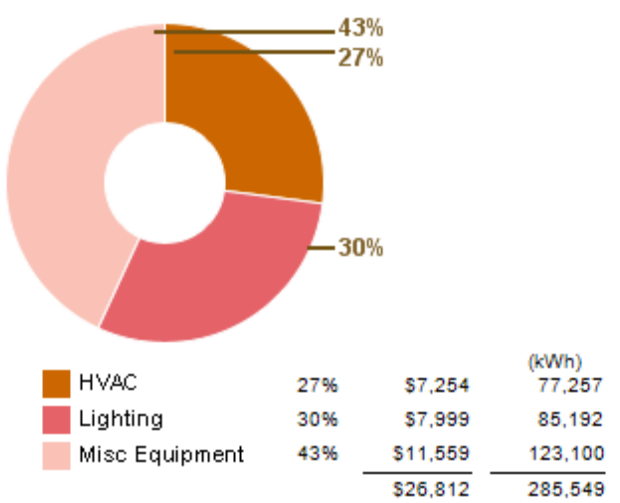

Fig.39: Energy Use: Electricity

\section{CONCLUSIONS AND RECOMMENDATIONS}

In the above context and applied energy modeling on the revised building according to LEED rating system requirement and versus to the outputs of the original building energy modeling it is clear that: Increasing the envelope window sizing (Fig.35, 36) as per the proposed elevation to achieve the required natural daylight, outdoor space connectivity with unobstructed sight of green areas and preventing and decreasing the infiltration of solar radiation inside the building through window openings (according to LEED requirements) which results in increasing in the required heat, ventilating and air condition HVAC which needed to keep the indoor environment is suitable for occupant inside the building quality view, air quality and thermal comfort ( temperature, humidity, or carbon dioxide control,...etc.) which needed for employee productivity and healthy environment.

In light of mentioned paper' context and its sequence, the main Conclusions could be identifies as follows:

- LEED challenge is an integrative effort to transform the way and methodology build environments from individual building to get neighborhoods and even entire communities are designed, constructed and operated with full respect of the environment conservation which is shift practice towards higher performance, lower environment impacts and ultimately regenerative building.

- The LEED Rating System is a tool that a design team uses in order to insure that a project's green features are properly designed, constructed, and accounted for.

- Sustainability is the ability of the current generation to meet its own needs without compromising the ability of future generations to meet their needs.

- Green buildings perform better than conventional ones where Green buildings save energy, use less water, generate less waste and provide higher levels of indoor quality and comfort over conventional design and construction practices and provide higher levels of occupant satisfaction with regards to air quality and lighting, where studies indicate significant gains with occupant productivity and show that these benefits can translate into a $2 \%$ to $16 \%$ increase in employee productivity (Fig.38, 39).

- The perspective of Sustainability improvements as an added feature of a building is an additional cost, often leads to conclusions that green buildings cost slightly more than conventional buildings, with estimates ranging from $2 \%$ to more than $5 \%$. If, however, energy improvements considered as part of an integrative design, therefore new savings often balances the added costs (Fig.38, 39).

- Occupants of green buildings are typically exposed to far lower levels of indoor pollutants and have significantly greater satisfaction with air quality and lighting than occupants of conventional buildings (Fig.33), which leads to increase occupant productivity and reduces absenteeism of employee. 
- In terms of the built environment and ensure that buildings and communities create value for all occupants and stakeholders, not just a restricted few, Triple Bottom Line (People, Planet, Profit) consideration should be implemented and considered throughout the entire life-cycle of a building.

- Economic benefits of Green building include reduce the operating cost, enhance asset/profits, improve employee satisfaction and productivity and optimize life cycle economic performance throughout the entire life cycle of a project.

- Health and Community benefits of Green building are improve air and thermal and acoustic environment, occupant comfort, satisfaction and health in addition to minimize strain on local infrastructure and contribute to overall quality of life (Fig.37).

- Environmental Benefits of green building enhance and protect ecosystem and biodiversity, improve air and water quality, reduce solid waste and conserve natural resources.

\section{REFERENCES}

1. U.S. GBC (US GREEN BUILDING COUNCIL), LEED reference guide for Building Design and Construction Rating System for New and Major Renovation Building V4, $1^{\text {st }}$ October 2014.

2. De Hartog, J.J., H. Boogaard, H. Nijland, and G. Hoek, Do the Health Benefits of Cycling Outweigh the Risks? Environmental Health Perspectives 118(8), 2010.

3. U.S. EPA (U.S. Environmental Protection Agency), Light-Duty Automotive Technology, Carbon Dioxide Emissions, and Fuel Economy Trends, May 2014.

4. American Physical Society, Energy Future: Think Efficiency, September 2008.

5. Parker, D.C., The Corporate Garden, in D. Relf (ed.), The Role of Horticulture in Human Well-Being and Social Development, Portland, Oregon: Timber Press, 1990.

6. U.S. EPA (U.S. Environmental Protection Agency), Health Buildings Healthy People: A Vision for the 21st Century, U.S EPA, October 2001. 